\title{
LOS DELITOS DE OMISIÓN IMPROPIA COMO DELITOS ESPECIALES Y DE DOMINIO POSITIVO DEL HECHO. REPERCUSIONES EN MATERIA DE AUTORÍA Y PARTICIPACIÓN.
}

\author{
María José RODRÍGUEZ MESA \\ PROFESORA TITULAR DE DERECHO PENAL \\ UNIVERSIDAD DE CÁDIZ
}

\begin{abstract}
SUMARIO: I. Delimitación y determinación de la autoría en comisión por omisión. I.I. La ostentación de un especial deber de actuar como requisito de la autoría. Los delitos de omisión impropia como delitos especiales. I.2. La determinación positiva del hecho como criterio determinante de la autoría. Los delitos de omisión impropia como delitos de dominio. II. Las formas de autoría en comisión por omisión. II.I. Coautoría. II.2. Autoría mediata. III. La participación omisiva. III.I. La exclusión de la inducción omisiva. III.2. La participación omisiva (cooperación necesaria y complicidad). III.3. La responsabilidad del garante como partícipe. III.3.I. La realización de una contribución de partícipe. III.3.2. La falta de acceso al tipo. III.4. La participación del no garante.
\end{abstract}

RESUMEN: Una de las cuestiones más arduas de los delitos de omisión impropia es la delimitación de la autoría y la participación, discutiéndose incluso la posibilidad de que pueda distinguirse entre ambas. La diversidad de las soluciones propuestas en esta materia es el reflejo de las distintas bases metodológicas adoptadas en la construcción dogmática de los delitos de omisión impropia. En este trabajo se parte de la configuración de los delitos de omisión impropia como delitos especiales y de dominio positivo del hecho, lo que implica, por una parte, la delimitación del círculo de posibles autores; y de otra, la necesidad de que el autor en comisión por omisión ostente un dominio o control del hecho idéntico al autor comisivo. Ello tiene importantes repercusiones en materia de autoría y participación.

PALABRAS ClAVE: Omisión impropia, delitos especiales, dominio del hecho, autoría, participación.

ABSTRACT: One of the most difficult questions of commission by omission crimes is the definition of author and participant, discussing even the possibility that it can distinguish between the two. The diversity of the solutions proposed in this area is a reflection of the different methodological basis adopted in the construction dogmatic commission by omission crimes. In this paper commission by omission crimes are considerate as special crimes and positive control. This means, on the one hand, the delimitation of the circle of potential authors, and the other, the need for the omissive author to have an identical control fact that commisive author. This has major implications in terms of authorship and participation.

KEYwORDS: Commission by omission, special crimes, positive control, authorship, participation. 


\section{Delimitación y determinación de la autoría en comisión por omisión}

I.I. La ostentación de un especial deber de actuar como requisito de la autoría. Los delitos de omisión impropia como delitos especiales.

Frente a los delitos comunes en los que cualquiera puede ser autor del delito, en los delitos especiales el círculo de posibles autores está limitado a los sujetos que reúnen la cualidad exigida por el tipo penal (intranei). Al resto de sujetos, que sin ostentar dicha cualidad, intervengan en el delito (extranei), éste no les podrá ser imputado a título de autor, ni siquiera cuando hayan ostentado un dominio esencial y positivo del hecho como puede ser la efectiva realización material de la acción típica.

Para que el omitente pueda responder como autor, tanto la jurisprudencia como la doctrina exigen pacíficamente que el sujeto tuviera el deber de evitación del resultado; esto es, que ostente un deber de garante basado en la ley, el contrato o la conducta precedente. Aunque entiendo que la infracción del especial deber de garante no es suficiente para que el resultado sea imputable al omitente en comisión por omisión, parece que a partir de tal exigencia los delitos de comisión por omisión aparecen configurados tanto en nuestro ordenamiento jurídico como en todos aquellos en los que por vía legal o doctrinal se exige la titularidad de este deber por parte del autor, como delitos especiales.

Esta afirmación depende, en todo caso, de lo que se entienda por delito especial o delicta propia. Si por tal se admite, con la doctrina mayoritaria, aquél en el que el ámbito personal de la autoría se encuentra restringido a un determinado círculo de personas, no existe inconveniente alguno en afirmar que los delitos de comisión por omisión son delitos especiales: el autor, además de dominar positivamente y realizar la acción típica, ha de tener un especial deber jurídico de actuar (en virtud de ley, contrato o injerencia).

En contra de su caracterización como delitos especiales se ha objetado que en la medida en que tanto en la realización activa de un delito como en la comisión por omisión el sujeto activo tiene que haber creado un riesgo típico, resulta lógico pensar que si para la realización de un delito de resultado mediante un hacer no se requiere posición de garante alguna, ésta tampoco se ha de exigir para su comisión por omisión. En efecto, el hecho de que para que la omisión sea equivalente a la comisión sea preciso que el sujeto asuma el compromiso de neutralizar un riesgo no es razón suficiente para convertir a los delitos de comisión por omisión en delitos especiales ${ }^{\mathrm{I}}$. En la medida en que cualquiera puede estar, en principio, en condiciones de asumir el concreto compromiso, cualquiera puede ser sujeto activo. Desde esta perspectiva, y acorde con la definición de delitos especiales que aquí se ha asumido, lo consecuente sería afirmar que los delitos de comisión por omisión serán delitos especiales o comunes en función de si los tipos especiales de referencia son o no, a su vez, de autoría restringida.

Esta solución, sin embargo, tropieza frontalmente con la necesidad de acudir a la especial relación del autor respecto del bien jurídico como forma de restringir el ámbito de la autoría ${ }^{2}$ y que se traduce en la exigencia de que el autor ostente algunos de los deberes de

${ }^{I}$ Véase más ampliamente RODRÍGUEZ MESA, M.J., La atribución de responsabilidad en comisión por omisión, Navarra, Aranzadi, 2005, págs. I2I y ss.

${ }^{2}$ Véase ZAFfaroni, E.R., Teoría del delito, Buenos Aires, Ediar, I973, pág. 375. 
garante a los que se refiere la doctrina y la jurisprudencia. De ahí que haya que descartar la autoría en comisión por omisión cuando existan dudas acerca de si el sujeto ostenta o no tal deber. Ahora bien, el hecho de que los delitos de comisión por omisión -como sucede con muchos otros delitos especiales- se relacionen exclusivamente con un deber especial que pesa sobre el autor no significa, como se pretende por parte de los defensores de la categoría de los Plifchtdelikte, que el deber especial absorba todo el injusto, sin necesidad de constatar la lesión o peligro para el bien jurídico. En estos delitos hay que comprobar tanto la lesión al bien jurídico que el legislador ha querido evitar al tipificar el comportamiento como delito, como el hecho desvalorado previamente por el legislador que indica que el único que puede convertir, por omisión, esa lesión en delito es el sujeto que ostenta un determinado deber ${ }^{3}$.

Desde esta perspectiva, no son trasladables a nuestro ordenamiento jurídico construcciones monistas como las llevadas a cabo en Alemania por SCHÜNEMANN o FREUND, en las que se pretende una explicación de la autoría en comisión por omisión

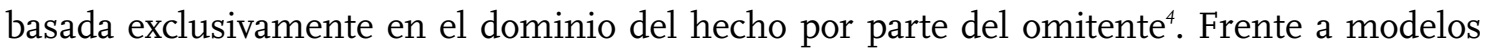
monistas (basados exclusivamente en la infracción del deber o en el dominio del hecho), la concreta elaboración doctrinal y aplicación jurisprudencial de la comisión por omisión en el ordenamiento jurídico español -la equiparación del marco penal solo puede venir justificada desde la identidad normativo-estructural del delito en comisión por omisión con el correspondiente delito comisivo- requiere un modelo aditivo en el que junto a los elementos objetivos de la autoría -en este caso, la ostentación de un especial deber de actuar-, deba verificarse el dominio positivo del hecho o control del suceso típico para afirmar la autoría: ni un especial deber del autor sin dominio objetivo y positivo del hecho, ni un dominio del hecho sin titularidad del deber permiten afirmar la autoría en comisión por omisión ${ }^{5}$. En este sentido, puede afirmarse que la lesión del deber especial será un presupuesto necesario, pero no suficiente para afirmar la autoría ; así, el principio según el cual en los delitos especiales solo pueden ser autores los titulares de deberes especiales, no significa que tales titulares de deberes sean siempre autores ${ }^{7}$, o al menos, autores de un delito en comisión por omisión ${ }^{8}$.

${ }^{3}$ Véanse al respecto QUINTERo OLIVARES, G., Los delitos especiales y la teoría de la participación en el Derecho
Penal Español, Barcelona, Cymys, I974, págs. 40-4I; y FERRÉ OlIVÉ, J.C., «Autoría y delitos especiales», AAVV
(Coord. Nieto Martín), Homenaje al Dr. Marino Barbero Santos. In memoriam, Vol. II, Cuenca, coeditado por las Universidades de Castilla-La Mancha y Salamanca, 200I, pág. IOI7.

${ }^{4}$ Aunque desde perspectivas muy distintas, véanse sChÜnEmAnN, B., Grund und Grenzen, cit., passim; y FREUND, G., Erfolgsdelikte und Unterlassen, Colonia, Berlín, Bonn y Munich, Carl Heymanns, I992, passim.

${ }^{5}$ Como ha señalado OCTAVIO DE TOLEDO Y UBIETO (La prevaricación del funcionario público, Madrid, Instituto de Criminología de la Universidad Complutense, I980, pág. 229), el pensamiento del bien jurídico, entendido en el sentido de los delitos de dominio del hecho, resulta siempre necesario.

${ }^{6}$ Véanse expresamente en este sentido DÍAZ y GARCÍA CONLLEDO, M., La autoría en Derecho penal, Barcelona, PPU, I99I, pág. 6I6; HERNÁNDEZ PLASENCIA, J.U., La autoría mediata en Derecho penal, Granada, Comares, I996, pág. 3I6; BOLEA BARDón, C., Autoría mediata en Derecho penal, Valencia, Tirant lo Blanch, 2000, págs. 438-439. GÓMEZ BENITEZ, («El dominio del hecho en la autoría. Validez y límites», $A D P C P$, I984, pág. I55) también requiere para los delitos especiales impropios, además de la infracción del deber, el dominio del hecho.

${ }^{7}$ QUINTERO OlIVARES, G., Los delitos especiales y la teoría de la participación, cit., págs. IO2-IO3.

${ }^{8}$ Precisamente esta idea es la que lleva a que un cada vez más significativo sector de nuestra doctrina venga distinguiendo entre los verdaderos supuestos de comisión por omisión -en los que junto a la titularidad del deber el omitente ostenta el dominio o control del hecho-, y aquellos otros supuestos en los que el titular del deber no ostenta un dominio actual del hecho -relegados a la consideración de omisiones de garante no 
I.2. La determinación positiva del hecho como criterio determinante de la autoría. Los delitos de omisión impropia como delitos de dominio.

Desde el modelo aditivo de la autoría en comisión por omisión que aquí se viene defendiendo, la titularidad del deber infringido es por sí misma insuficiente para certificar la autoría ${ }^{9}$. Es necesario, además, que el autor, tal y como se desprende del artículo $28 \mathrm{CP}$, «ejecute la acción típica»; es decir, mate, lesione, detenga, etc., a través de su omisión.

Rechazada la posibilidad de que la infracción de un deber pueda erigirse en un criterio autónomo de autoría, la cuestión se centra ahora primeramente en establecer cuáles son los criterios en cuya virtud se puede afirmar que, a la luz del artículo $28 \mathrm{CP}$, un sujeto «realiza el hecho»; posteriormente habrá que decidir cuándo se puede decir que, con la aplicación de tales criterios, el omitente «ejecuta la acción típica» ${ }^{\circ \circ}$.

Para quienes, como aquí se hace, partimos de la necesaria equivalencia estructural y material entre los delitos de comisión por omisión y los delitos comisivos, no hay ningún inconveniente en requerir para la autoría que el omitente ejerza el control o dominio del hecho típico. Ahora bien, ello no significa que sea suficiente con un dominio negativo del hecho, entendido como mera evitabilidad, para que el omitente sea responsable a título de autor $^{\text {II }}$. La determinación positiva del hecho que requiere la autoría es distinta y más que el mero poder o capacidad de impedir o contener el curso del hecho, no ya con una actividad positiva, sino con la simple pasividad. Tal dominio negativo, como señala LUZÓN PEÑA, puede ser característico de una forma más simple de participación como la cooperación necesaria, pero en modo alguno puede ser suficiente para afirmar la autoría ${ }^{\mathrm{I2}}$.

La autoría precisa, pues, también en comisión por omisión, que el omitente ejerza un dominio sobre el hecho -determinación positiva y actual del hecho típico-comparable al que debe poseer el autor por comisión. Dado que el autor por comisión domina el suceso lesivo por medio de sus actividades corporales y, por lo tanto, a través del dominio sobre su

equiparables a la comisión-. Por todos véase silva SÁnCHEZ, J., El delito de omisión. Concepto y sistema, $2^{\mathrm{a}}$ ed., Montevideo-Buenos Aires, Editorial B De F/Julio César Faira Editor, 2003, págs. 339 y ss.

${ }^{9}$ Como señalan muÑoz CONDE y GARCíA ARÁn (Derecho penal. Parte General, Valencia, Tirant lo Blanch, 2002, pág. 449), «en algunas formas de delito (imprudentes, comisión por omisión, especiales) el dominio del hecho tiene que ser completado por otros criterios específicos, como infracción del deber extrapenal, posición de garante, etc. En estos supuestos autor en sentido estricto es quien, además de dominar el hecho materialmente, tiene un deber específico de impedir el resultado típico. Por tanto, la infracción del deber (de diligencia, de la posición de garante) no es por sí suficiente para fundamentar la autoría».

${ }^{\text {10 }}$ No se trata aquí de analizar -ni siquiera de exponer- las posturas de la ciencia penal y de la jurisprudencia sobre los criterios decisivos de la autoría. Para más información al respecto, véase la obra monográfica de DÍAZ Y GARCíA CONLLEDO, M., La autoría en Derecho penal, cit.

"I «La suposición de un dominio del hecho 'negativo' es solo una ilusión, pues el dominio del hecho no surge de la posibilidad de retirar el aporte, sino de participar contribuyendo con un aporte». BACIGALUPO ZAPATER, E., «Notas sobre el fundamento de la coautoría en el Derecho Penal», en Poder Judicial, N 3I, I993, pp. 37 y ss.

${ }^{12}$ LUZÓN PEÑA. D., «La determinación objetiva del hecho. Observaciones sobre la autoría en delitos dolosos e imprudentes de resultado», Estudios Penales, Barcelona, PPU, I99I, págs. 205-206. Siguiendo su criterio DÍAZ Y GARCÍA-CONLLEDO, M., La autoría en Derecho penal, cit., págs. 669-670, y PAREDES CASTAÑón, J.M., en PAREDES CASTAÑÓN, J.M./RODRÍGUEZ MONTAÑÉs, T., El caso de la colza: responsabilidad penal por productos adulterados o defectuosos, Valencia, Tirant lo Blanch, I995, pág. I54. En este mismo sentido, señala DíEZ RIPOLLÉS («Una interpretación provisional del concepto de autor en el nuevo Código Penal», RDPC, I/1998, pág. 43, nota 53) como la distinción entre un dominio positivo y un dominio negativo del hecho podría explicar adecuadamente cual es la diferencia entre el control propio de la autoría, el dominio positivo, y el de las modalidades más graves de participación, el dominio negativo. 
cuerpo, una omisión equivalente a la comisión presupone un control actual sobre el suceso equiparable en intensidad a ese control ${ }^{13}$.

Entre los autores españoles, GRACIA MARTÍN propone la determinación del dominio positivo del hecho en la omisión a partir de la idea de dominio social, como exigencia previa de determinados tipos que delimita las concretas posibilidades de acción con dominio finalista del hecho del sujeto que extiende su poder a un concreto ámbito ${ }^{\text {I4 }}$. Según esta tesis, frente a los delitos comunes en los que por regla general es el propio autor el que organiza la situación personalmente, en los delitos de dominio social la situación típica está ya previamente organizada -y por ello descrita y acotada por el tipo-, y el autor tiene que realizar una acto personal de incorporación de esa situación organizada -situación de domino social- a su esfera de dominio personal. Únicamente en esas condiciones le será posible tomar la decisión de lesionar el bien jurídico y de ejecutarla a continuación mediante la actualización del dominio del hecho. El dominio social opera, pues, como presupuesto del dominio final del hecho. Así, para que quien ostenta una posición de garante, en virtud del dominio social, pueda llegar a ser considerado autor en comisión por omisión será preciso además que se haya asumido el dominio efectivo de la causa fundamental del resultado. De ahí que la ostentación del dominio social solo nos señale el autor idóneo, pero no todavía al autor.

En la construcción que propone GRACIA MARTÍN, la afirmación de autoría en comisión por omisión va a requerir además del dominio social del hecho -entendido como el conjunto de condiciones que fundamenta la relación específica de dependencia- el dominio efectivo sobre la causa fundamental del resultado. Tal dominio efectivo sobre la causa del resultado existiría, según este autor, cuando quepa afirmar que la realización de la acción omitida produce en general con certeza definitivamente y sin que sean necesarias acciones ulteriores intermedias el resultado salvador. Desde esta perspectiva, la participación por omisión solo será posible en aquellos supuestos en los que la acción omitida simplemente hubiera dificultado el resultado salvador ${ }^{15}$.

A pesar de lo atractiva que resulta la idea de ampliar el criterio del dominio social a los delitos de comisión por omisión, la propuesta de GRACIA MARTín al recurrir en última instancia para afirmar el dominio al criterio de la mayor o menor capacidad para evitar el resultado, se hace acreedora de las mismas críticas que cualquiera de las tesis que toman como punto de partida la causalidad hipotética.

No obstante, a partir de la idea de la asunción de un compromiso de actuar como barrera de contención frente a riesgos concretos se puede decir que el omitente ejerce un dominio del hecho idéntico al que ejerce el autor directo en los delitos comisivos. El omitente, una vez asumido el riesgo, posee -con respecto a ese riesgo- algo más que un mero dominio potencial negativo: está objetivamente en condiciones de dominar, controlar

\footnotetext{
${ }^{13}$ SCHÜnEmANN, B., «Sobre el estado actual de la dogmática de los delitos de omisión en Alemania», en Gimbernat/Schünemann/Wolter (eds.): Omisión e imputación objetiva en Derecho Penal. Jornadas HispanoAlemanas en Homenaje al Profesor Claus Roxin con motivo de su investidura como Doctor Honoris Causa por la Universidad Complutense de Madrid, Servicio de Publicaciones Facultad de Derecho UCM y Centro de Estudios Judiciales, Madrid, I994, pág. 22.

${ }^{14}$ Véase ampliamente, GRACIA MARTín, L., «La comisión por omisión en el Derecho penal español», Actualidad Penal, I995, págs. 702 y ss.

${ }^{15}$ GRACIA MARTíN, L., «La comisión por omisión en el Derecho penal español», cit., pág. 7I2.
} 
o decidir positivamente el curso de los acontecimientos hacia el resultado, de modo que al igual que en los delitos comisivos se puede afirmar que la realización del hecho queda en sus manos: que es él quien con su omisión determina objetiva y positivamente el resultado típico.

En los supuestos en los que el proceso del riesgo que posteriormente se realiza en el resultado -y que el omitente se ha comprometido a controlar- responde a una situación de caso fortuito o a la naturaleza misma de las cosas, la doctrina no suele tener problemas en afirmar la autoría del omitente. En estos casos, en los que el compromiso del sujeto determina que no haya peligro -o que si lo hay no supere determinados niveles-, si el sujeto omite de pronto cumplir con el compromiso asumido, entonces y por ello -es decir, no por algo diverso cronológicamente y en origen- la propia omisión crea (normativamente) el peligro, hasta ese momento inexistente o controlado, pues permitiendo que surja, lo desencadena y descontrola, lo que quiere decir que para volver a controlarlo habría que hacer algo, si todavía es posible ${ }^{\mathrm{r} 6}$.

Menos unánime es la respuesta cuando de lo que se trata es de determinar la responsabilidad del omitente cuando el hecho principal es en sí delictivo. Así, para un sector de la doctrina la persona que comete activamente el hecho es quien tiene el dominio del hecho, careciendo de él el garante que no impide, con su omisión, la comisión del delito. En consecuencia, y en virtud de una rigurosa aplicación del criterio del dominio del hecho $^{\mathrm{r} 7}$, el omitente garante responde, por regla general, como partícipe ${ }^{\mathrm{r} 8}$, admitiéndose su autoría solo en aquellos casos en los que no se le pueda imputar a nadie la creación activa del riesgo. Es obvio que con este modo de determinar la autoría en comisión por omisión se produce una paradoja difícil de resolver. Así, no se entiende por qué ha de responder como autor el padre que no impide que el perro rabioso del vecino muerda a su hijo, y como partícipe si es el vecino, y no su perro, quien golpea al niño. Con independencia de cuál sea la solución adecuada, lo que parece claro es que en ambos casos el dominio que sobre el hecho ostenta el padre es idéntico, por lo que idéntico ha de ser también el título en cuya virtud responda penalmente.

Y es que si lo que determina el dominio del hecho del omitente, y por tanto su responsabilidad a título de autor, es la posición que como consecuencia del compromiso asumido ostenta con respecto del bien jurídico o de la fuente de riesgo en cuestión, difícilmente puede ser relevante a estos efectos la procedencia del proceso de riesgo. Desde el momento en que lo determinante para afirmar la autoría es el control o dominio actual y positivo del proceso lesivo $-\mathrm{y}$ no el mero dominio potencial negativo-, siempre que se pueda afirmar que el omitente ostenta tal dominio habrá de responder como autor, y ello con independencia de que el hecho principal sea también atribuible a título de autoría comisiva a un tercero. Imagínese el caso del escolta que, pudiendo impedirlo, permite que un tercero mate al sujeto cuya vida e integridad se había comprometido a salvaguardar. No se trata aquí de un dominio negativo del hecho, de un mero poder de evitar. El escolta, al

\footnotetext{
${ }^{16}$ LUZÓN PEÑA, D., «La participación por omisión en la jurisprudencia reciente del TS», Estudios penales, Barcelona, I991, pág. 240.

${ }^{17}$ Desde esta perspectiva se considera que desde el momento en el que hay un tercero que comete activamente el hecho, éste ostenta -frente al dominio potencial y negativo del omitente- un dominio actual y positivo, por lo que es suposición, y no la del omitente la que puede fundamentar la autoría.

${ }^{18}$ Así, JESCHEK, MAURACH, y, aunque desde una perspectiva diferente, GIMBERNAT ORDEIG.
} 
asumir el riesgo que para la vida de su cliente podía provenir de la actuación de un tercero, está en condiciones de decidir el proceso lesivo. Así, cuando ante una situación efectiva de riesgo omite la contención o neutralización del riesgo que previamente se había comprometido a neutralizar, se puede afirmar que realiza el hecho, pues en ese momento ostenta el control o dominio positivo del curso causal.

A esta solución se le podría objetar que frente a las restantes formas de intervención de un sujeto en el hecho, la conducta de autoría se caracteriza por ser la única conducta cuya aportación causal al curso fáctico posee una significación jurídico-penal autónoma respecto de las aportaciones de otros sujetos ${ }^{19}$. Desde esta perspectiva se podría decir que la omisión del escolta en el ejemplo propuesto, en la medida en que depende de la acción de un tercero que provoque o configure el curso causante del resultado, solo es calificable de participación. Y tal argumentación sería correcta si efectivamente el escolta participara con su omisión en un hecho ajeno. Pero, en la medida en que su compromiso de control va referido al riesgo que se produce en el resultado -al proceso lesivo principal-, el escolta no interviene en el hecho delictivo comisivo, sino que realiza el suyo propio, domina su propio hecho ${ }^{20}$.

Desde esta perspectiva, y dado que la equivalencia de la comisión por omisión con los supuestos comisivos se construye en referencia a los supuestos de autoría ${ }^{21}$, siempre que lo asumido por el omitente sea el control del riesgo que se realiza en el resultado se podrá afirmar la ostentación del dominio, tal y como ha sido delimitado, del hecho típico. Así, el omitente en comisión por omisión responderá por regla general como autor, pero no por el hecho de haber infringido un deber, sino porque domina o controla el suceso del mismo modo que el autor por comisión.

\section{Las formas de autoría en comisión por omisión}

En los casos en los que el proceso causal lesivo no es de por sí delictivo, el omitente -en caso de darse los requisitos anteriormente examinados- responde como autor único. Frente a estos supuestos, que son los más comunes en la práctica, puede ocurrir que el dominio positivo del hecho radique tanto en el omitente como en un tercero que interviene activa u omisivamente, a su vez, en la realización del hecho. Las combinaciones, como puede imaginarse, son múltiples: desde un supuesto de autoría accesoria hasta otro de autoría mediata, pasando por hipótesis de coautoría.

\footnotetext{
${ }^{19}$ Sobre este criterio de la autoría véanse LUZÓN PEÑA; D., «La determinación objetiva del hecho...», cit., págs. 2I7-2I8; DÍAZ Y GARCÍA CONLLEDO, M., La autoría en Derecho penal, cit., pág. 692; y PAREDES CASTAÑÓN, J.M., en PAREDES CASTAÑ́́N, J.M./RODRÍGUEZ MONTAÑÉS, T., El caso de la colza: responsabilidad penal por productos adulterados o defectuosos, cit., págs. I50-I5I.

${ }^{20}$ Véase al respecto SILVA SÁNCHEZ, J.M., «Aspectos de la comisión por omisión: Fundamento y formas de intervención. El ejemplo del funcionario penitenciario», Cuadernos de Política Criminal, i989, págs. 388-389.

${ }^{2 \pi}$ Como indica SILVA SÁNCHEZ («Aspectos de la comisión por omisión: Fundamento y formas de intervención. El ejemplo del funcionario penitenciario», cit., pág. 388), el juicio de identidad estructural, al proyectarse sobre la realización de los tipos de la Parte Especial, incorpora necesariamente el elemento de la autoría. Los tipos de la Parte Especial los realizan solo los autores; de ahí que una omisión idéntica a la realización comisiva del tipo de la Parte Especial es, así, una omisión en concepto de autor.
} 


\section{II.I. Coautoría}

Frente a la autoría inmediata o primaria -derivada de los respectivos tipos penalesel legislador contempla en el art. 28 CP otra forma de estructuración del comportamiento humano consistente en la ejecución conjunta o co-ejecución del hecho típico. Quienes siguen en este punto la versión más estricta de la tesis del «dominio funcional del hecho» consideran coautor a todo el que, en virtud de un reparto de papeles entre los diversos intervenientes, tiene en sus manos durante la ejecución la posibilidad de co-decidir sobre la marcha del hecho hacia la consumación ${ }^{22}$. Consecuentemente se afirma la coautoría tanto de quien hace un aporte decisivo durante la ejecución para la consumación del hecho, como de quien teniendo el dominio funcional del hecho no lo hubiese evitado o tratado de aminorar.

No obstante, si se niega la posibilidad de que la autoría pueda venir determinada por un dominio negativo del suceso típico, siendo necesario el control objetivo y positivo del hecho, también en los casos de coautoría habrá que exigir tal determinación positiva, no siendo suficiente para ser imputado como coautor tener simplemente el poder sobre el «no», sobre la no producción del hecho típico ${ }^{23}$. En la ejecución conjunta del hecho, como forma de autoría, es preciso que el dominio alcance el control que caracteriza al dominio en la autoría: tener el pleno poder de decisión y configuración sobre el sí y el cómo de la ejecución del hecho típico ${ }^{24}$. Y tal poder de dominio y configuración de los hechos lo tiene, según la doctrina y la jurisprudencia mayoritaria, todo aquel que en la fase de ejecución le corresponde llevar a cabo, de acuerdo con el plan delictivo conjunto, una contribución independiente y esencial para la realización del tipo penal, cuya no prestación conduce al desbaratamiento del plan final ${ }^{25}$.

De tal configuración de la coautoría se deriva la necesidad de que solo puedan ser considerados coautores quienes intervengan durante la fase ejecutiva. Como advierte PÉREZ ALONSO, solo a partir de este momento adquieren relevancia jurídico-penal los sucesos de actuación, es decir, solo a partir de aquí se realiza conjuntamente el hecho punible ${ }^{26}$. Ahora bien, la exigencia de una intervención en fase ejecutiva no significa necesariamente que todos los coautores hayan de realizar actos que desde un punto de vista formal sean ejecutivos $^{27}$. La coautoría, como su propio nombre indica, es algo más que la suma de

\footnotetext{
${ }^{22}$ Véanse al respecto MUÑOZ CONDE, F., /GARCÍA ARÁN, M., Derecho penal. Parte General, cit., págs. 45I-453.

${ }^{23}$ DíAZ y García Conlledo, M., «La influencia de la teoría de la autoría (en especial, de la coautoría) de Roxin en la doctrina y la jurisprudencia españolas. Consideraciones críticas», Revista Nuevo Foro Penal, Vol. 7, No. 76, 20II, pág. 39 .

${ }^{24}$ Véase LUZÓN PEÑA, D., «La determinación objetiva del hecho...», cit., págs. 205-206.

${ }^{25}$ Véase PÉREZ ALONSO, E.J., La coautoría y la complicidad (necesaria) en Derecho penal, Granada, Comares, I998, págs. 24I.

${ }^{26}$ PÉREZ ALONSO, E.J., La coautoría y la complicidad (necesaria) en Derecho penal, cit., I998, págs. 236-240. Véase asimismo la bibliografía que cita en la pág. 236, notas 95 y 96.

${ }^{27}$ En contra de esta posibilidad, DíEZ RIPOLLÉS («Una interpretación provisional del concepto de autor en el nuevo Código Penal, $R D P C$, I/I998, pág. 4I) rechaza «las propuestas de incluir en la coautoría contribuciones esenciales al delito llevadas a cabo de modo simultáneo a la realización del hecho típico por otros sujetos, en virtud de que con ellas se posee el dominio funcional del hecho y sin que sea óbice para ello el con tales contribuciones no se acceda en ningún momento a los elementos típicos y/o ejecutivos». En sentido similar, aunque restringiendo la posibilidad de admitir coautoría a los supuestos en los que se ejecuta el acto típico nuclear, DÍAZ Y GARCÍA CONLLEDO, M., «Autoría y participación», La Ley, II-I996, pág. 4; del mismo, La autoría en Derecho en Derecho penal, cit., págs. 677 y ss.
} 
autorías individuales: se trata de la realización conjunta de los actos ejecutivos, del acceso parcial al tipo ${ }^{28}$. Precisamente por ello, no es preciso que cada uno de los coautores ejecute parcialmente el hecho típico, siendo suficiente con que su aportación contribuya de forma esencial a la ejecución o realización conjunta del hecho típico ${ }^{29}$. Desde esta perspectiva es coautor tanto el que sujeta a la víctima del homicidio mientras que B apuñala, como quien vierte cincuenta gramos de veneno en el vaso de leche que va a tomar la víctima sabiendo que B ha vertido los otros cincuenta que son necesarios para que la dosis sea letal. Tanto en un caso como en otro, y en la medida en que no hay forma de cometer ese homicidio concreto si A no sujeta a la víctima o no vierte su dosis de veneno, hay un co-dominio positivo y material del hecho, condicionado por la actividad de todos los intervinientes en la ejecución del mismo. El hecho está en las manos de todos ellos, porque cada uno presta una contribución que decide el sí y el cómo de la co-realización del hecho ${ }^{30}$.

Desde esta perspectiva ha de rechazarse la posibilidad de calificar como coautor al escolta que permitía que un tercero disparase contra su cliente. En este caso, y a diferencia de lo que ocurre en los verdaderos supuestos de coautoría, no es apreciable un co-dominio del hecho. El escolta y el sujeto que dispara contra su cliente no dominan el hecho de forma conjunta, sino totalmente aislada. Mientras que el dominio del escolta se refiere al proceso lesivo cuya omisión permite que se ponga en marcha, el dominio del tercero va referido al proceso causal que el mismo pone en marcha. En este caso, y haciéndonos eco de la expresión utilizada por ZAFFARONI, falta «la distribución funcional de la empresa criminal»; se trata, pues, de un claro ejemplo de autoría accesoria o simultánea, en la que varias personas, independientemente unas de otras producen el resultado típico ${ }^{35}$.

Ahora bien, el hecho de que en este caso concreto se esté ante un supuesto de autoría accesoria no significa negar la posibilidad -como hacen los defensores de la tesis de la infracción del deber- de admitir la coautoría en comisión por omisión ${ }^{32}$. En efecto, para los partidarios de determinar la autoría en comisión por omisión en base exclusivamente al criterio de la «infracción del deber», la hipótesis de una pretendida coautoría es sencillamente impensable. Y es que, como señala BACIGALUPO ZAPATER, la parcialización

\footnotetext{
${ }^{28}$ Terminología esta última utilizada por DÍEZ RIPOLLÉS, J.L., «Una interpretación provisional del concepto de autor...», cit., pág. 35 .

${ }^{29}$ En este sentido, MUÑoz CONDE y GARCíA ARÁN (Derecho penal. Parte General, cit., pág. 452) quienes aprecian también la coautoría en los casos en que se produce un reparto de papeles entre los diversos intervinientes en la realización de un delito, de tal modo que alguno o algunos de los coautores ni siquiera están presentes en el momento de su ejecución. Aunque, desde puntos de partidas distintos, llegan a la misma solución CEREZO MIR, J., «Autoría y participación en el Código Penal vigente y en el futuro Código Penal», en Mir Puig (ed.), La reforma del Derecho penal, Barcelona, I980, pág. 238; MIR PUIG, S., Derecho penal. Parte General, Barcelona, Bellaterra, I999, pág. 387; GÓMEZ RIVERO, M.C., «Regulación de las formas de participación intentada y de la autoría y participación», La Ley, I-I996, pág. 4; y PÉREZ ALONSO, J.E., La coautoría y la complicidad (necesaria) en Derecho penal, cit., pág. 265.

${ }^{30}$ PÉREZ ALONSO, J.E., La coautoría y la complicidad (necesaria) en Derecho penal, cit., pág. 265.

${ }^{31}$ Ambos son, como señala SÁNCHEZ-VERA GÓMEZ-TRELLES (Delito de infracción de deber y participación delictiva, Madrid, Marcial Pons, 2002, pág. 201), «figuras centrales del suceso, independientes la una de la otra, o dicho de forma más exacta -desde un punto de vista estrictamente normativo-, figuras centrales de dos sucesos diferentes».

${ }^{32}$ En este sentido advierte SILVA SÁNCHEZ («Aspectos de la comisión por omisión: fundamento y formas de intervención. El ejemplo del funcionario penitenciario», Cuadernos de Política Criminal, I989, pág. 389, nota IO2), como tanto en la situación de concurrencia entre hecho principal comisivo y hecho omisivo «idéntico», como la de la concurrencia de varios omitentes en condiciones de comisión por omisión, la calificación de coautoría o autoría accesoria dependerá en última instancia de la existencia o no de acuerdo.
} 
de la infracción del deber «resulta, desde todo punto de vista, incompatible con un hecho que se caracteriza, precisamente, porque toda infracción del deber emergente de una posición de garante no admite subdivisión alguna» ${ }^{33}$.

Si lo determinante de la autoría, por el contrario, no es la infracción del deber sino el dominio del hecho, para la afirmación de coautoría en comisión por omisión es irrelevante el hecho de que la infracción del deber sea indivisible -pues, al igual que ocurre en algunos delitos especiales cada uno de los coautores ha de infringir su propio deber-. Lo realmente importante es que mediante su contribución activa u omisiva codominen positivamente la realización del hecho típico. Para que sea apreciable la coautoría en comisión por omisión es preciso, pues, que la omisión se produzca durante la fase de ejecución del hecho y que mediante la no neutralización del riesgo que el omitente se había comprometido a contener se preste una contribución independiente y esencial al hecho que suponga un codominio positivo del hecho típico, adoptada mediante un acuerdo o decisión conjunta en el marco del plan delictivo global, concurriendo también la posición de garante así como las especiales cualidades personales requeridas ${ }^{34}$, en su caso, por el correspondiente tipo penal ${ }^{35}$.

Desde la exigencia de un codominio del hecho en la fase ejecutiva que responda a un plan común, para la apreciación de coautoría en comisión por omisión es indiferente que se dé entre un «autor» comisivo y un «autor» omisivo, o entre dos autores omisivos; y en este último caso que el deber sea uno personal, o permita su infracción conjunta ${ }^{36}$. En cualquier caso, y dada la excepcionalidad de un co-dominio del hecho en fase ejecutiva, van a ser muy escasos en la práctica los supuestos susceptibles de ser calificados como de coautoría en comisión por omisión. Un caso de coautoría en comisión por omisión sería, por ejemplo, el de los dos únicos cuidadores del enfermo que, previo acuerdo, no le dan de comer. En este caso, el proceso que ha causado la muerte del enfermo ha sido dominado o controlado conjuntamente -y no solo accesoriamente- por ambos omitentes.

\section{II.2. Autoría mediata}

Son varios los argumentos en los que se apoya la doctrina para negar la posibilidad de autoría mediata en comisión por omisión. Así, la figura de la autoría mediata resulta incompatible con la construcción de la autoría en comisión por omisión exclusivamente en base a la infracción de un deber de actuar. Y es que, en efecto, si en los delitos de infracción de deber el dominio del hecho no es criterio determinante tampoco servirá como pauta para

\footnotetext{
${ }^{33}$ BACIGAlupo ZAPATER, E., Delitos impropios de omisión, Buenos Aires, Dykinson, I970, pág. I42. En idéntico sentido SÁNCHEZ-VERA GÓMEZ-TRELLES, J., Delito de infracción de deber y participación delictiva, cit., pág. 202.

${ }^{34}$ En este sentido advierte JESCHECK (Tratado de Derecho penal. Parte General, Granada, Comares, I993, pág. 6I7) como al constituir la coautoría una forma de autoría, solo puede ser coautor quien también es autor idóneo respecto a las demás contribuciones al hecho.

${ }^{35}$ Para esta definición se ha tomado como referencia la definición de coautoría aportada por PÉREZ ALONSO, J.A., La coautoría y la complicidad (necesaria) en Derecho penal), cit., pág. 393.

${ }^{36}$ Atendiendo a la naturaleza del deber infringido, Roxin (Autoría $y$ dominio del hecho en Derecho penal, $7^{a}$ ed., Madrid, Marcial Pons, 2000, pág. 39I) rechaza la coautoría cuando el deber se refiera tan solo a la persona individual -como, por ejemplo, en el pago de alimentos-, admitiéndose tan solo cuando se da la determinación del resultado por quebrantamiento conjunto de un deber común. Es decir, la coautoría en comisión por omisión queda limitada en la construcción de ROXIN a los supuestos en los que varias personas se encuentran sujetas a un mismo y único deber.
} 
afirmar la autoría mediata y, con ello, no es posible establecer una vinculación -en base al criterio del dominio del hecho- entre el hombre de detrás y el de delante ${ }^{37}$. Desde la perspectiva de la teoría del delito de infracción de deber que un omitente sea autor mediato cuando el instrumento realiza un acto positivo es, como señala BACIGALUPO ZAPATER, absolutamente imposible en tanto omisión y dominio del hecho no pueden coexistir ${ }^{38}$.

Si, por el contrario, se admite que la autoría en comisión por omisión también precisa de la constatación de un dominio material y positivo del hecho -de un control del suceso típico por parte del omitente-, no hay ningún obstáculo, en principio, para compatibilizar el dominio funcional del hecho que supone la autoría mediata con el dominio que se ejerce a través de la omisión. Desde este punto de vista, un sector de la doctrina española viene admitiendo la posibilidad de la autoría mediata cuando alguien, infringiendo su deber de garante, no impide la acción delictiva del instrumento ${ }^{39}$.

Cierto que el no impedir -estando obligado a ello- que otro cometa un delito no tiene por qué significar la atribución del resultado al omitente a título de autor directo. Para ello, como ya se ha tenido ocasión de analizar, se requiere algo más que un mero dominio negativo del hecho: es preciso que el omitente tome en sus manos el riesgo; es decir, sea dueño y señor del proceso lesivo. Ahora bien, en la medida en que la autoría mediata es, ante todo, una forma de autoría, el autor mediato debe ejercer también -al igual que el autor directo- un dominio positivo del hecho. La única diferencia del autor mediato frente al inmediato radica, pues, en la forma de ejercer el dominio: dominio de la acción ( $u$ omisión) propia en el primer caso, y dominio de la voluntad del instrumento en el segundo. Si el dominio negativo no es suficiente para afirmar la autoría mediata en comisión por omisión, que en todo caso requiere el ejercicio de un control positivo sobre el hecho típico, se plantea la cuestión de cómo distinguir, en su caso, entre autoría directa y autoría mediata.

La figura de la autoría mediata se construye para resolver los supuestos en los que alguien se sirve de un instrumento para la realización del hecho delictivo. En estos casos se produce una escisión entre quien «realiza formalmente los actos ejecutivos» (autor inmediato), y quien domina positivamente el suceso a través del dominio sobre la voluntad del instrumento (autor mediato). En los supuestos de omisión «idénticos» a la comisión, el resultado es imputable al omitente a título de autor (directo) no porque haya realizado -en sentido formal- los actos ejecutivos, sino porque a través de su omisión crea un riesgo estructuralmente idéntico al que se crea mediante la realización activa de los actos ejecutivos. La afirmación de la autoría directa en comisión por omisión se sustenta, pues, en el control o dominio del proceso lesivo principal, y ello con independencia de que este acontecer se base en las fuerzas de la naturaleza o en una conducta humana ${ }^{40}$.

Piénsese así en el caso de A, quien tras poner una sustancia venenosa -que fácilmente puede ser confundida con agua- en un vaso y dejarlo encima de la mesa sin

\footnotetext{
${ }^{37}$ SÁNCHEZ-VERA GÓMEZ-TRELLES, J., Delito de infracción de deber y participación delictiva, cit., pág. 207.

${ }^{38}$ BACigalupo ZAPATER, E., Delitos impropios de omisión, cit., pág. I44.

39 Así maurach, R., Derecho Penal. Parte General, 2, Buenos Aires, Astrea, 1995, pág. 327; MIR PUIG, S., Derecho penal. Parte General, cit., pág. 379; y HeRnÁNDEZ PLASENCIA, J.U., La autoría mediata en Derecho penal, Granada, Comares, I996, pág. 316.

${ }^{40}$ Por todos Roxin, C., Autoría y dominio del hecho en Derecho penal, cit., pág. 5II.
} 
indicación alguna, observa cómo B, creyendo que se trata de agua, utiliza la sustancia del vaso parar preparar la comida que va a comer $C$, quien muere como consecuencia de la ingesta del veneno. Si A pone el veneno precisamente para que B lo utilice de la forma en que lo hace y mate a $\mathrm{C}$, no hay inconveniente alguno en afirmar la autoría mediata de A, pero comisiva y no en comisión por omisión. Si, por el contrario, el dolo surge al observar cómo B se dispone a utilizar la sustancia del vaso (dolo subsequens) la omisión de A fundamenta una autoría directa, pues ostenta directamente (y no a través del instrumento) un dominio sobre el riesgo penalmente relevante.

Entiendo, pues, que en consecuencia con lo dicho hasta ahora ha de negarse la posibilidad de admitir autoría mediata en comisión por omisión. Pero no por una cuestión de incompatibilidad o imposibilidad dogmática, sino por una cuestión eminentemente práctica: el no impedir, por el garante, que un tercero cometa un delito será constitutivo de autoría -en todo caso inmediata- cuando el sujeto se haya comprometido a evitar el riesgo que de la actuación de un tercero pueda derivarse para el bien jurídico en cuestión. Cuando, por el contrario, el omitente no se haya comprometido -o su compromiso no vaya referido a las actuaciones de terceros ${ }^{41}-\mathrm{su}$ intervención, al faltar el dominio sobre el hecho principal lesivo, podrá ser constitutiva de participación, pero en modo alguno de autoría, ni inmediata ni mediata.

\section{La participación omisiva}

En esta materia la cuestión se centra en determinar si la omisión del garante es siempre constitutiva de autoría, o si, por el contrario, puede dar lugar a la apreciación de alguna de las formas de participación que prevé el Código Penal; esto es, inducción (determina a quien tiene el dominio del hecho a cometer un delito), cooperadores necesarios y cómplices.

\section{III.I. La exclusión de la inducción omisiva}

Con independencia de la solución a la que se llegue con respecto las demás formas de participación, la doctrina -salvo contadas excepciones ${ }^{42}$ - niega la posibilidad de admitir la inducción omisiva ${ }^{43}$. La inducción, como de acuerdo con un criterio doctrinal y jurisprudencial extendido señala QUINTERO OLIVARES ${ }^{44}$, consiste en determinar consciente e

${ }^{4 \mathrm{r}}$ Ello suele ocurrir cuando, como veremos posteriormente, el sujeto se compromete no a contener los riesgos que se puedan derivar para un bien jurídico, entre ellos los procedentes de terceros; sino a evitar los riesgos que puedan derivarse, en general, de una fuente de peligro que el omitente se compromete a controlar.

${ }^{42}$ RUdolPHi (en Rudolphi/Horns/Samson/Günther, Systematischer Comentar zum Strafgesetzbuch (6a ed), Neuwied-Kriftel-Berlin, Luchterhand, I995, Rn 42, previos al parágrafo I3), por ejemplo, admite que existe inducción en comisión por omisión cuando el garante no impide que otro sujeto induzca activamente. Siguiéndole JAKOBS, G., Derecho penal. Parte general, cit., págs. IO29-IO30; SÁNCHEZ-VERA GÓMEZ-TRELLES, J., Delito de infracción de deber y participación delictiva, cit., pág. 2I3. Admiten también la inducción omisiva, aunque con importantes reservas, SCHMIDHÄUSER, E., Strafrecht, Allgemeiner Teil ( $2^{\mathrm{a}}$ ed), Tubinga, I984, I3/IO; y VOGEL, J., Norm und Pflicht bei den unechten Unterlassungsdelikten, Berlin, I993, pág. 288 y ss.

${ }^{43}$ En contra de la inducción omisiva véase ampliamente GÓMEZ RIVERO, M.C., La inducción a cometer el delito, Valencia, Tirant lo Blanch, I995, págs. 200 y ss.

${ }^{44}$ QUINTERO OLIVARES, G., «Los confines de la inducción: de la responsabilidad penal a la responsabilidad moral», en Díez Ripollés/Romeo Casabona/ Gracia Martín/Higuera Guimerá, La ciencia del Derecho penal ante el nuevo siglo. Libro Homenaje al profesor doctor D. José Cerezo Mir, Madrid, Tecnos, 2003, pág. 92I. 
intencionadamente a otra persona cometer un delito, pero sin participar en su ejecución. Asimismo, de la redacción misma del art. 28 CP se deriva la necesidad de que la determinación sea «directa».

Pues bien, la omisión -en cuanto comportamiento pasivo- difícilmente puede determinar de forma directa la comisión de un delito. Así, ejemplos como el propuesto por VOGEL del padre que tras haber sido informado por el hijo de su intención de quemar la finca en el caso de que el padre no guarde la libreta de ahorros, deja la libreta donde estaba a pesar de que siempre la retiraba ${ }^{45}$, no son válidos para afirmar la instigación omisiva: si el padre es garante frente a las actuaciones del hijo o de la indemnidad de la finca será autor en comisión por omisión, mientras que si no ostenta una especial posición de garantía no existirá responsabilidad penal. En este caso, y a diferencia de los verdaderos supuestos de instigación, la omisión del padre no hace surgir en el hijo la voluntad delictiva; éste ya había resuelto delinquir condicionando su ejecución a la interposición por parte del padre de una condición impeditiva.

\section{III.2. La participación omisiva (cooperación necesaria y complicidad)}

El primer grupo de casos que suele manejarse en relación con la participación omisiva es el relativo a la calificación de la omisión del garante cuando un tercero realiza activamente el hecho. Ya se ha visto cómo la admisibilidad y, en su caso, el concreto alcance de la participación omisiva en este primer grupo de casos depende, en gran medida, de cuál sea el fundamento de la equiparación entre la omisión y la comisión activa.

Así, quienes consideran que los delitos de comisión por omisión son delitos de infracción de un deber -o, al menos, priman la posición de garante frente a cualquier otro criterio- afirman la autoría del omitente siempre que el tipo en cuestión pueda realizarse por omisión. Para quienes, por el contrario, parten de una aplicación rigurosa de la teoría del dominio del hecho, el omitente -al tener solo un dominio potencial y negativo del hecho- es frente al autor comisivo -quien ostenta un dominio positivo y actual- un mero

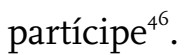

En tercer lugar para quienes en la línea marcada por KAUFMANN aceptan una diversidad en las situaciones de garantía, el omitente responderá en términos generales como autor cuando el garante responda a una especial relación respecto de la existencia del bien jurídico defendido (función de protección). Habrá participación omisiva, en cambio, cuando el garante, que debe impedir la desestabilización de un foco de peligro o el ataque delictivo de terceros, posibilita la lesión del autor (función de control) ${ }^{47}$.

\footnotetext{
${ }^{45}$ VOGEL, J., Norm und Pflicht bei den unechten Unterlassungsdelikten, cit., pág. 290.

${ }^{46}$ Según esta concepción, el dominio del hecho únicamente pasa al omitente cuando el actuante deja de dominar el hecho: en este caso su dominio pasaría de potencial a fáctico y, en consecuencia, permitiría afirmar la autoría del omitente. Véase al respecto JESCHECK, H-H., Tratado de Derecho penal. Parte General, Granada, Comares, 2003 , pág. 635 .

${ }^{47}$ SCHÖNKE/SCHRÖDER/CRAMER/HEINE., Strafgesetzbuch Kommentar, $24^{\text {a }}$ ed., München, I99I, Rn. IO5 y sS., previo a parágrafo 25. En términos similares, SCHÜNEMANN, B., Grund und Grenzen der Unechten Unterlassungsdelikte, Göttingen, I97I, pág. 377. A conclusiones parecidas, aunque tomando como punto de partida el concepto negativo de acción, llega HERZBERG, R.D., Die Unterlassung im Strafrecht und das Garantenprinzip, Berlin, I974, pág. 260.
} 
Desde el punto de vista de la tesis que se fija en la identidad estructural entre omisión y comisión como criterio de equivalencia es posible, todavía, una última solución a este primer grupo de casos. En coherencia con los presupuestos de los que parte, el omitente garante será autor cuando su conducta equivalga a la autoría comisiva -esto es, cuando mediante la omisión se cree o incremente el riesgo penalmente relevante-, y será partícipe por omisión cuando la omisión equivalga exactamente a la participación activa simplemente se favorezca la creación o incremento de un riesgo ajeno- $-^{48}$.

Ahora bien, si se quiere ser consecuente con lo que significa la exigencia de identidad estructural, el criterio de equivalencia no puede llevarnos a graduar la responsabilidad del garante en función de la relación de causalidad hipotética que se dé en cada caso. Así, por ejemplo, en España, el Tribunal Supremo afirma indistintamente la existencia de autoría o cooperación necesaria en comisión por omisión «cuando pueda formularse un juicio de certeza, o de probabilidad rayana en la certeza, sobre la eficacia que habría tenido la acción omitida para la evitación del resultado ${ }^{49}$. Comisión por omisión en grado de complicidad o cooperación no necesaria existirá, por su parte, cuando el mismo juicio asegure que la acción omitida habría dificultado de forma sensible la producción del resultado, lo que equivaldría a decir que la omisión ha facilitado la producción del resultado en una medida que se puede estimar apreciable» ${ }^{50}$.

Efectivamente, si se pretende afirmar la equivalencia a partir del criterio de la «causalidad hipotética», entonces debe ser decisivo para la autoría que la acción esperada hubiera evitado el resultado ${ }^{5 \mathrm{~T}}$. Del mismo modo, y si se parte en la complicidad activa de la creación de un riesgo de lesión mediata al bien jurídico, entonces debe ser decisiva para la complicidad omisiva la posibilidad del garante de disminuir este riesgo de lesión ${ }^{52}$. En consecuencia, si se demuestra que la omisión solo ha podido dificultar la acción, y en ningún caso impedirla, entonces, aunque el sujeto sea garante, no respondería como autor

\footnotetext{
${ }^{48}$ En este sentido se pronuncia SILVA SÁNCHEZ ( «Aspectos de la comisión por omisión: fundamento y formas de intervención. El ejemplo del funcionario penitenciario», cit., pág. 389) al afirmar la participación de un sujeto en comisión por omisión en aquellos casos en que «la identidad estructural no se establece con la realización activa de un tipo de la Parte Especial, sino con el tipo del partícipe...». Expresamente en términos similares LUZÓN PEÑA, D., «La participación por omisión en la jurisprudencia reciente del TS», cit., pág. 235; DÍAZ Y GARCÍA CONLLEDo, M., «Omisión de impedir delitos no constitutiva de participación por omisión. ¿Un caso de dolo alternativo?... », Poder Judicial (24), I99I, pág. 208.

49 De la calificación de cooperación necesaria ha querido extraer la doctrina que el TS se adhiere a las conclusiones de la tesis del dominio del hecho, en cuya virtud siempre que haya un tercero actuante el omitente será partícipe. Los cierto, sin embargo, es que el TS español alude a la cooperación necesaria como una forma de autoría y no como una forma de participación, utilizando indistintamente los términos autoría y cooperación necesaria. Ilustrativa al respecto la STS (Sala de lo Penal, Secc. $\mathrm{I}^{\mathrm{a}}$ ), $\mathrm{n}^{\circ}$ 5903/I99I, de 3I de octubre, Ponente: Exmo. Sr. MARTÍNEZ PEREDA RODRÍGUEZ, en la que se considera que «tal actitud omisiva, cuando por su condición de madre se encontraba obligada a actuar, velando por la salud e integridad de la hija, de la que se hallaba constituida en garante por mandato legal, la constituye en coautora del delito de lesiones (...) en la categoría de cooperadora necesaria...». En un sentido similar, la STS (Sala de lo Penal, Secc. I ${ }^{a}$ ), n ${ }^{\circ}$ 283/20io, de 26 de marzo, Ponente: Exmo. Sr. SÁNCHEZ MELGAR.

${ }^{50}$ STS (Sala de lo Penal, Secc. $\mathrm{I}^{\mathrm{a}}$ ), $\mathrm{n}^{\circ}$ 7I96/2000, de 9 de octubre, Ponente: Exmo. Sr. JIMENEZ VILLAREjO. Véase asimismo la STS (Sala de lo Penal, Secc. $\mathrm{I}^{\mathrm{a}}$ ), $\mathrm{n}^{\circ}$ 42/1998, de I2 de enero, Ponente: Exmo. Sr. GRANADOS PÉREZ, en la que expresamente se mantiene la posibilidad, por parte del garante, de dificultar la producción del resultado, «permite afirmar la causalidad hipotética en que se asienta la complicidad».

${ }^{51}$ Con este planteamiento, la STS (Sala de lo Penal, Secc. $\mathrm{I}^{\mathrm{a}}$ ), $\mathrm{n}^{\mathrm{o}} 5229 / 2000$, de 26 de junio, Ponente: Exmo. Sr. SÁNCHEZ MELGAR llega a la conclusión de que «el conocimiento y pasividad (de la madre)...la convierte, a la luz de la doctrina jurisprudencial de esta Sala, en autora por comisión por omisión, dada su posición de garante».
}

${ }^{52}$ VÉASE LÓPEZ PEREGRIN, M.C., La complicidad en el delito, Valencia, Tirant lo Blanch, I997, pág. 345, nota 205. 
sino como partícipe ${ }^{53}$. De injusta, por no graduar la participación en el hecho del autor, califica PORTILLA CONTRERAS la opción contraria ${ }^{54}$.

En mi opinión, esta construcción de la autoría y la participación en comisión por omisión responde, sin embargo, a un vicio de planteamiento. Y es que, ni la «no evitación del resultado por el garante» es en todo caso comisión por omisión, ni el criterio de la causalidad hipotética desempeña función alguna en el juicio de equivalencia ${ }^{55}$. Además, pasa por alto que la identidad necesaria para aplicar al delito en comisión por omisión la misma pena que al delito comisivo activo, como se verá más adelante, va referida al autor, por lo que difícilmente podrá graduarse su responsabilidad en función de cuál haya sido su contribución al hecho.

El criterio de la equivalencia sirve también a GIMBERNAT ORDEIG para afirmar participación en comisión por omisión -y no autoría- cuando el garante no evita la comisión del delito por un tercero. La intervención activa de un tercero impide, a su juicio, afirmar que la propia omisión crea el peligro de lesión para el bien jurídico, y en consecuencia afirmar la autoría en comisión por omisión ${ }^{56}$. En términos similares se pronuncia LUZÓN PEÑA exigiendo además, para que la pasividad del omitente sea algo más que pura omisión y constituya participación omisiva, que con la no evitación o no obstaculización del delito se ayude o facilite la realización del tipo al autor ${ }^{57}$.

En efecto, y en la medida en que el juicio de identidad estructural se proyecta sobre la realización del tipo por el autor ${ }^{58}$, la omisión estructural idéntica (comisión por omisión) a la realización comisiva del tipo de la Parte Especial es una omisión en concepto de autor ${ }^{59}$. En consecuencia, y como hacen GIMBERNAT ORDEIG y LUZÓN PEÑA, habrá que excluir la autoría en comisión por omisión -admitiendo en su caso un supuesto de participación omisiva- cuando no pueda afirmarse que el riesgo penalmente ha sido (normativamente) creado mediante la omisión.

Lo que ya no está tan claro, sin embargo, es que la creación del riesgo a través de la omisión dependa en modo alguno de que intervenga o no un tercero actuante. Difícilmente se puede afirmar que el padre que dolosamente permite que su hijo pequeño se arroje al río es autor porque con su omisión crea el peligro para el bien jurídico, y al mismo tiempo

\footnotetext{
${ }^{53}$ Así, en la STS (Sala de lo Penal, Secc. Iª), no 3523/I99I, de 22 de junio, Ponente: Exmo. Sr. ROMÁn PUERTA, se condena al padre como autor de un delito de lesiones en comisión por omisión pues, «no cabe imaginar que la esperada (por obligada) acción protectora del padre no hubiera podido evitar tal resultado...Considerada en la forma expuesta, la conducta del procesado no cabe valorarla -desde el punto de vista de la causación del resultado- como meramente favorecedora del mismo, sino como condición necesaria... No puede hablarse pues, en modo alguno, de mera complicidad».

${ }^{54}$ PORTILLA CONTRERAS, G., «La participación omisiva en delitos de resultado y simple actividad», AAVV, Homenaje a Torío, Granada, Comares, I990, pág. 463.

${ }^{55}$ Véase RODRÍGUEZ MESA, M.J., La atribución de responsabilidad en comisión por omisión, cit., págs. I48 y I49.

${ }^{56}$ GIMBERNAT ORDEIG, E., «Recensión del libro «Delitos impropios de omisión de E. Bacigalupo», ADPCP, I970, pág. 726.

${ }^{57}$ LUZÓN PEÑA, D.M., «La participación por omisión en la jurisprudencia reciente del TS», cit., pág. 244. En términos similares DÍAZ Y GARCÍA CONLLEDO, M., «Omisión de impedir delitos no constitutiva de participación por omisión...» cit., pág. 2 Io.

${ }^{8}$ DÍAZ Y GARCÍA CONLLEDO, M., «Omisión de impedir delitos no constitutiva de participación por omisión...» cit., pág. 209.

59 SILVA SÁNCHEZ, J.M., «Aspectos de la comisión por omisión: fundamento y formas de intervención. El ejemplo del funcionario penitenciario», cit., pág. 388.
} 
negar que la omisión cree el peligro cuando el padre dolosamente lo que permite es que un tercero arroje a su hijo al río. O la omisión crea el riesgo en ambos casos, o no lo crea en ninguno; lo inadmisible es mantener una postura diferenciadora.

Si se acepta como punto de partida que el criterio de equivalencia -referido al autor, y no al partícipe- viene dado por el compromiso del garante de actuar a modo de barrera de contención frente a riesgos concretos que amenazan o puedan amenazar a un bien jurídico, la realización de «ese» riesgo en el resultado imputable a la vulneración del compromiso dará lugar, por regla general, a una responsabilidad a título de autor. El omitente no responde en estos casos por su intervención en un riesgo ajeno, sino por el riesgo normativamente creado con su omisión; y es en ese sentido en el que su aportación al hecho es una aportación de autor y no de partícipe ${ }^{60}$.

\section{3. La responsabilidad del garante como partícipe}

El hecho de que el omitente (en comisión por omisión) responda en la mayoría de los casos como autor no excluye, sin embargo, la posibilidad de admitir supuestos en los que la responsabilidad del omitente lo sea a título de partícipe. Son supuestos en los que, a pesar de que se produce la vulneración del compromiso del garante que permite afirmar la identidad estructural entre la omisión y la comisión, aquél -en contra de la regla generalno responde como autor sino como partícipe. Ello sucede en primer lugar cuando el compromiso del garante vaya referido a la contención del riesgo derivado de un partícipe en el hecho ajeno. También responderá como partícipe cuando, dados los elementos exigidos por el tipo penal, el garante no tiene acceso a la autoría.

\section{III.3.I. La realización de una contribución de partícipe}

La imputación del resultado a título de autor exige, entre otros requisitos, que el dominio o control del sujeto se ejerza sobre el riesgo que se realiza directa o inmediatamente en el resultado ${ }^{61}$. Cuando el control va referido a otros riesgos que contribuyen a que el resultado se realice, solo se puede exigir responsabilidad a título de partícipe.

Dado que en los delitos de comisión por omisión el dominio o control del suceso se expresa a través del compromiso del garante, éste solo podrá responder como autor cuando su compromiso vaya referido a la contención del riesgo principal, del riesgo que se realiza en el resultado. Cuando, por el contrario, su compromiso se refiera a la neutralización de un riesgo que solo de modo indirecto o mediato se realiza en el resultado, responderá como partícipe $^{62}$. Y ello porque mientras que en el primer caso la omisión muestra identidad

\footnotetext{
${ }^{60}$ Como se verá más adelante, el omitente garante que asume el riesgo interviene como autor en comisión por omisión en un hecho propio, y como partícipe por omisión en el hecho ajeno; absorbiendo la autoría omisiva a la participación omisiva.

${ }^{6 r}$ Para la relación entre el dominio del hecho y la imputación objetiva VÉASE HERNÁNDEZ PLASENCIA, J.U., «Imputación objetiva versus dominio del hecho», en Díez Ripollés/Romeo Casabona/ Gracia Martín/Higuera Guimerá, La ciencia del Derecho penal ante el nuevo siglo, cit., págs. 735 y ss.

${ }^{62}$ Véanse RUDOLPHI, H-J., Systematischer Comentar zum Strafgesetzbuch, cit., Rn 42, previos al parágrafo I3; ROXIN, C., Leipziger Comentar, ( $\mathrm{II}^{\mathrm{a}}$ ed), Berlin-New Cork, I993, Rn 2IO, parágrafo 25; SILVA SÁNCHEZ, J.M., «Aspectos de la comisión por omisión: fundamentos y formas de intervención. El ejemplo del funcionario
} 
estructural con la conducta activa de autoría (dominio del riesgo que se realiza en el resultado), en el segundo la identidad se da con conductas de participación (favorecer o facilitar mediante una contribución a los hechos el riesgo ajeno) ${ }^{6_{3}}$. En estos supuestos el omitente responderá como cooperador necesario o no necesario en función de la esencialidad para la realización del hecho ajeno del riesgo que se había comprometido a contener ${ }^{64}$.

A esta postura se le ha objetado que no permite la autoría mediata ${ }^{65}$. Y en efecto, en la medida en que se califica de partícipe a quien, habiéndose comprometido a hacerlo, no contiene a un tercero que interviene activamente en el delito, no se puede negar que esta construcción responde a la misma estructura que la autoría mediata. No obstante, y en contra de lo que pudiera parecer, esta tesis no impide la explicación de la autoría mediata, que en todo caso quedaría excluida en comisión por omisión, pero por otras razones distintas. Y ello porque la posibilidad de la autoría mediata sigue quedando abierta, al menos en teoría ${ }^{66}$, para aquellos supuestos en los que el compromiso del omitente se refiere a la contención del riesgo proveniente de un tercero (enajenado, menor, en situación de error, etc.) que actúa como ejecutor material del hecho típico.

\section{III.3.2. La falta de acceso al tipo}

Junto al control del suceso típico, la autoría requiere un primer componente de acceso al tipo, en virtud del cual se pretende expresar de manera general cuáles son las diferentes vías admisibles para predicar de una conducta, o de una parte de ella, que se corresponde con la descrita en el tipo ${ }^{67}$. Señala en este sentido DÍEZ RIPOLLÉS, como el dolo y los restantes elementos subjetivos de lo injusto, la cualidad personal del sujeto activo en los delitos especiales y la realización personal del tipo exigible en los delitos de propia mano, son elementos de acceso restringido que impiden afirmar la autoría de quien teniendo el control del suceso típico carece de ellos ${ }^{68}$. Así, y aunque el garante ostente en virtud del compromiso asumido el control del suceso típico, si no posee las características especiales exigidas por el tipo no puede responder como autor. Por los mismos motivos tampoco es posible afirmar la autoría del garante cuando el tipo en cuestión impide el acceso omisivo ${ }^{69}$ :

penitenciario», cit., págs. 389-390; LÓPEZ PEREGRín, M.C., La complicidad en el delito, Valencia, I997, págs. 347348; y SÁNCHEZ-VERA GÓMEZ-TRELLES, J., Delito de infracción de deber y participación delictiva, cit., págs. 200-20I.

${ }^{6_{3}}$ En un sentido similar, aunque desde un presupuesto distinto, ROBLES PLANAS, R., «Los dos niveles del sistema de intervención en el delito (El ejemplo de la intervención por omisión) », In Dret, 2/20I2, pág. II.

${ }^{64}$ Ya será cuestión, como señala LUZÓN PEÑA («La participación por omisión en la jurisprudencia reciente del TS», cit., pág. 246), de aplicar el criterio que se considere más correcto -mediante una valoración ex ante o ex post, la necesidad en abstracto o en concreto, para el si y el cuándo o también para el cómo de los hechos, o mediante el criterio de los bienes escasos-, para determinar si dicha contribución es o no decisiva para el autor y si, por tanto, se considera cooperación necesaria o complicidad.

${ }_{5}^{65}$ Véase en este sentido díAZ y GARCía CONLLEDo, M., «Omisión de impedir delitos no constitutiva de participación por omisión...cit., pág. 210, nota I6.

${ }^{66}$ En la práctica se ha visto como esto supuestos habrán de ser calificados de autoría inmediata y directa.

${ }^{67}$ DÍEZ RIPOLLÉS, J.L., «Una interpretación provisional del concepto de autor...», cit., pág. 34.

${ }^{68}$ DÍEZ RIPOLLÉS, J.L., «Una interpretación provisional del concepto de autor...», cit., pág. 50.

${ }^{69}$ Como advierte DÍEZ RIPOLLÉs («Una interpretación provisional del concepto de autor...», cit., pág. 38), «en los tipos que se detienen en la descripción de los elementos de la acción en sus medios comisivos, el aspecto de acceso tenderá a obtener un papel preponderante...». 
en estos casos la literalidad del precepto penal impide que al tipo en cuestión se pueda acceder en comisión por omisión ${ }^{70}$.

Frente a estos casos la doctrina mayoritaria en España -consecuente con el carácter secundario del concepto de participación- no tiene inconveniente en afirmar la responsabilidad del garante como partícipe por omisión en el hecho realizado por el tercero actuante $^{71}$. Y es que el garante que, habiéndose comprometido a hacerlo, no impide el riesgo para el bien jurídico proveniente de un tercero es, además de autor en comisión por omisión del hecho propio, partícipe por omisión en el hecho ajeno ${ }^{72}$. El garante, además de ser autor de su propio hecho, en la medida en que con su abstención elimina el obstáculo que su presencia o acción esperada supone para el delincuente se puede decir que facilita o favorece el delito, y en tal sentido que interviene como partícipe por omisión en el hecho ajeno.

En condiciones de acceso normal al tipo la autoría omisiva absorbe a la participación omisiva. Pero, cuando dada la falta de acceso al tipo no es posible afirmar la autoría, la omisión del garante puede fundamentar la responsabilidad por participación omisiva. En estos casos, al existir un nivel de control del suceso típico equivalente o muy cercano al de la autoría se puede decir que mediante su omisión el garante contribuye a la realización del tipo con una condición esencial, por lo que la calificación correcta en todos estos supuestos en los que lo único que falta es el acceso inmediato al tipo -pero no el control del sucesoes la de cooperación necesaria por omisión ${ }^{73}$.

\section{III.4. La participación del no garante}

Por las razones ya expuestas, han de ser rechazadas todas aquellas posturas que identifican la comisión por omisión con la «no evitación del resultado por el garante». Desde el punto de vista que aquí se viene defendiendo, y del mismo modo que la «no evitación del resultado por el garante» no es suficiente para fundamentar un supuesto de autoría en comisión por omisión, tampoco puede serlo para fundamentar un supuesto de participación.

Tal y como advierte LUZÓN PEÑA, para que la pasividad sea algo más que pura omisión y constituya participación omisiva, es preciso que equivalga exactamente a la participación activa. Así, pues, la no evitación o no obstaculización del delito solo constituirá cooperación, necesaria o no (complicidad), al delito si le ayuda o facilita la realización del tipo al autor ${ }^{74}$. Tal aseveración plantea a su vez dos cuestiones: en primer lugar, si la

${ }^{70}$ En este sentido señala la secc. $2^{a}$ de la AP de Barcelona (sentencia $156 / 1998$, de 20 de febrero), como al no ser factible en el hecho enjuiciado (la no denuncia por parte de la madre de las agresiones de las que era objeto su hijo pequeño por parte de su compañero sentimental) conjugar los verbos típicos en presencia del hecho omisivo que trata de subsumirse en él, no podrá afirmarse que la no evitación del resultado fue equivalente a su causación.

${ }^{71}$ Expresamente en contra de esta posibilidad SÁNCHEZ-VERA GÓMEZ-TRELLES, J., Delito de infracción de deber $Y$ participación delictiva, cit., págs. I99-200.

${ }^{72}$ Véase al respecto RoXin, C., Autoría Y dominio del hecho en Derecho penal, cit., págs. 517-518.

${ }^{73}$ Véase al respecto DíEZ RIPOLLÉS, J.L., « Una interpretación provisional del concepto de autor...», cit., pág. 37.

${ }^{74}$ LUZÓN PEÑA, D.M., «La participación por omisión en la jurisprudencia reciente del TS», cit., pág. 244. Exige también un favorecimiento positivo del hecho Roxin, C., Autoría y dominio del hecho en Derecho penal, cit., pág. 525 . 
participación omisiva exige, al igual que la autoría, que el omitente se encuentre en posición de garante; y, en segundo lugar, cuándo se puede decir que la omisión misma favorece o facilita el hecho ajeno.

En la respuesta a la primera de las cuestiones planteadas la doctrina española se encuentra dividida. Así, para un sector mayoritario de la doctrina española -y también para el TS- la línea que diferencia entre la participación omisiva y la omisión pura viene marcada por la posición de garante del omitente. Otra parte -minoritaria, por cierto- de la doctrina, sin embargo, admite la responsabilidad por la omisión de cualquier sujeto que favorezca o facilite el hecho delictivo ajeno ${ }^{75}$.

En mi opinión, y en el sentido de la segunda de las líneas doctrinales apuntadas, no existe ninguna razón legal, dogmática, ni práctica para excluir al no garante del ámbito de la participación omisiva. Por una parte, no se puede ignorar que la infracción del deber de garante que se requiere en la comisión por omisión ha de ir referida al autor, que es a quien va referido el tipo comisivo de la Parte Especial que se le pretende imputar en comisión por omisión; y en consecuencia no es extensible al partícipe.

Por otra parte, la actividad del partícipe no tiene necesariamente por qué ser causal respecto al resultado del hecho principal, siendo suficiente con que la conducta haya favorecido o facilitado de algún modo la acción del autor ${ }^{76}$. Por tanto, y a diferencia de lo que ocurre en los supuestos de autoría, la afirmación de la participación omisiva no precisa -al menos, necesariamente- del equivalente funcional de la causalidad activa que supone la posición de garante. Desde esta perspectiva quedan superados los inconvenientes dogmáticos para ampliar la participación omisiva a las contribuciones del «no garante».

Por último, y ya desde un punto de vista exclusivamente práctico, se ha objetado a la solución que aquí se propone que conduciría a resultados tan injustos como si se pretendiera castigar como autor de homicidio a cualquiera que no evitara una muerte ${ }^{77}$. Y es que, en efecto, si se admite como participación (cooperación necesaria o no necesaria) la omisión de dificultar la realización del delito se hace preciso recurrir a la posición de garante para evitar una ampliación excesiva del ámbito de la participación omisiva. Esta construcción debe ser, no obstante, rechazada, pues omitir dificultar el hecho -ni siquiera por el garante- no equivale en modo alguno a facilitarlo activamente ${ }^{78}$. Y en cualquier caso, advierte ROXIN, cuando falta ya la posibilidad de evitar el resultado -quedando la mera

\footnotetext{
${ }^{75}$ Véanse expresamente ROXIN, C., Autoría $y$ dominio del hecho en Derecho penal, cit., págs. 525 y ss; CóRDOBA RoDA, J., Notas al Tratado de Derecho penal de R. Maurach, T. II, Barcelona, I962; CEREZO MIR, J., «Autoría y participación en el Código penal vigente y en el futuro Código penal, en Mir Puig (ed.), La reforma del Derecho penal, Bellaterra, I980, pág. 244; OCTAVIO DE TOLEDO, E./HUERTA TOCILDO, S., Derecho penal. Parte general. Teoría jurídica del delito, Madrid, Ed. R. Castellanos, I986, pág. 590; LUZÓN PEÑA, D., «La participación por omisión en la jurisprudencia reciente del TS», cit., pág. 244 .

${ }^{76}$ En la doctrina española adoptan expresamente esta posición, GIMBERNAT ORDEIG, E., Autor $y$ cómplice en Derecho penal, Madrid, I966, pág. I72; CóRdoba RodA, J./RODríguez Mourullo, G., Comentarios al Código Penal, I, Barcelona, I972, pág. 890; GÓMEZ BeniTEZ, J.M., Teoría jurídica del delito. Derecho penal. Parte general, Madrid, I984, pág. 5I5; Сово DEL ROSAL, M./VIVES AnTón, T.S., Derecho penal. Parte general, Valencia, I996, pág. 688; y MIR PUIG, S., Derecho penal. Parte General, cit., pág. 392.

${ }^{77}$ VÉASE LÓPEZ PEREGRIN, M.C., La complicidad en el delito, cit., pág. 339.

${ }^{78}$ Véanse al respecto ROXIN, C., Autoría y dominio del hecho en Derecho penal, cit., pág. 529; LUZÓN PEÑA, D., «La participación por omisión en la jurisprudencia reciente del TS», cit., pág. 245. En términos parecidos DíAZ Y GARCÍA CONLLEDO, M., «Omisión de impedir delitos no constitutiva de participación por omisión...», cit., pág. 2IO.
} 
posibilidad de dificultarlo-, el Derecho no tiene motivos para exigir una intervención inútil ${ }^{79}$.

Y esto nos lleva directamente a la segunda de las cuestiones planteadas, la de cuándo afirmar que la omisión facilita o favorece el hecho delictivo ajeno. La participación, como señala, LUZÓN PEÑA, consiste en facilitar al autor la comisión del delito, sea mediante la entrega de un bien o la realización de una actividad o la remoción de un obstáculo. En la participación omisiva el omitente, al facilitar o quitar obstáculos a la acción del autor, contribuye a aumentar el peligro de la realización de la lesión.

La eliminación o remoción de obstáculos, como forma de favorecimiento, no debe ser confundida con la «no interposición de obstáculos» para la comisión de un delito ${ }^{80}$ : esto, por regla general, dará lugar a un supuesto de autoría en comisión por omisión cuando el omitente se hubiera comprometido frente al riesgo que pueda provenir para el bien jurídico de la actuación delictiva de un tercero; y a un delito de omisión pura -en su caso- (art. Io8 $\mathrm{CP}$ ) en los supuestos restantes. Así, en el ejemplo del vecino propuesto por ROXIN ${ }^{8 \mathrm{r}}$, si el vecino no acostumbraba a cerrar la puerta con llave y esa noche, aun sabiendo que con ello facilita la comisión del delito tampoco lo hace, no se puede decir que con su omisión haya facilitado o removido obstáculos para la comisión del delito: lo que hace mediante su omisión es no interponer obstáculos al delito, lo cual es insuficiente -al menos en el caso del no garante- para fundamentar una participación omisiva. Distinta es la situación si, como expone ROXIN en su ejemplo era costumbre del vecino el cerrar la puerta con llave: en este caso la inactividad sí que aparece como facilitamiento y favorecimiento positivo del hecho delictivo, pues el sujeto, en consideración al delito planeado omite una acción que estaba dispuesto a llevar al margen de toda comisión delictiva y que habría impedido o dificultado (ex ante) objetivamente la comisión del hecho ${ }^{82}$.

Desde este punto de vista, y aunque hay que reconocer que en la mayoría de las ocasiones el omitente partícipe va a ser a su vez garante, no existen argumentos concluyentes que excluyan, a priori, la posibilidad de apreciar la participación omisiva del no garante.

\footnotetext{
${ }^{79}$ ROXIN, C., Autoría y dominio del hecho en Derecho penal, cit., pág. 529.

${ }^{80}$ Véase DÍAZ Y GARCÍA CONLLEDO, M., «Omisión de impedir delitos no constitutiva de participación por omisión...», cit., pág. 210.

${ }^{81}$ «En una época de revueltas políticas se planea atentar contra un estadista. Como la casa de éste se encuentra bien vigilada por la policía, los terroristas deciden procurarse con ganzúas y en su caso con palancas la entrada de la casa contigua, ya anochecido, para desde su patio penetrar en la vivienda de la víctima. Al hacerlo son conscientes de que no es pequeño el riesgo de ser atrapados por la policía al irrumpir en la casa contigua. Sin embargo confían en no ser descubiertos, y como máximo, se les haga responder solo por el allanamiento intentado. A mediodía de la fecha prevista para el atentado el plan es descubierto por el morador de la casa vecina por circunstancias desconocidas para los conjurados. Éste es un enemigo acérrimo del estadista que desea fervientemente que el atentado tenga éxito. Por eso deja sin cerrar la puerta con llave, frente a lo que acostumbra, para que los terroristas, sin despertar sospechas, penetren y puedan acceder al patio, como efectivamente ocurre, pereciendo el estadista apuñalado por los conjurados». Roxin, C., Autoría y dominio del hecho en Derecho penal, cit., págs. 526-527.

${ }^{82}$ ROXIN, C., Autoría Y dominio del hecho en Derecho penal, cit., pág. 527.
} 